\title{
Apresentação do dossiê: A Historiografia sobre as Missões Jesuíticas: a Escrita e o Tempo
}

\author{
Alex Coello de la Rosa* \\ Universidad Pompeu Fabra, Barcelona, Catalunha, Espanha \\ Giovani José da Silva** \\ Universidade Federal do Amapá, Macapá, AP, Brasil \\ Maria Cristina Bohn Martins ${ }^{\star * *}$

O número que aqui apresentamos aos leitores da Revista Anos 90 é composto por sete trabalhos relativos ao Dossiê A Historiografia sobre as Missões Jesuiticas: a Escrita e o Tempo, além de dois artigos livres. Todos eles se debruçam sobre um tema cuja trajetória é tão extensa quanto volumosa: a atividade missionária da Companhia de Jesus, e a produção historiográfica a respeito dela.

Podemos dizer que a ação dos inacianos em relação às populações dos territórios não europeus, para onde eles se expandiram desde os inícios do século XVI, foi uma das marcas mais significativas da primeira globalização (ALMEIDA, 2010; ARANHA, 1998; CARNEIRO DA CUNHA, 1998; GRUZINSKI, 2004). Nos territórios do Novo Mundo, a nova Modernidade buscou ser, como afirmou Bartomeu Meliá (MELÍA, 2006), “sem limites”, uma vez que visava a agir sobre os colonos europeus, assim como sobre as populações ameríndias, trabalhando para uma transformação que se processava em todos níveis, na sociedade e na economia, na vida familiar e material, no espiritual e no simbólico. As suas "missões", especialmente aquelas que tinham por método a reducción a pueblos, foram uma singular "experiência de contato", cuja complexidade e cujos desdobramentos gerou perene interesse de especialistas de variados campos.

\footnotetext{
*Professor da Universidad Pompeu Fabra, Barcelona, Catalunha, Espanha. E-mail: alex.coello@upf.edu. Orcid: https://orcid.org/0000-0001-5079-6180.

** Professor da Universidade Federal do Amapá, Macapá, Brasil. E-mail: giovanijsilva@hotmail.com. Orcid: https://orcid.org/0000-0003-4906-9300.

*** Professora da Universidade do Vale do Rio dos Sinos, São Leopoldo, Brasil. E-mail: mcris@unisinos.br. Orcid: https://orcid.org/0000-0001-7835-9062.
} 
De uma perspectiva geral, aquilo que os jesuítas definiram como "missão por redução" pode ser entendida, assim, como um "fato social total”, não isenta de tensões.

No Brasil, os estudos sobre os vários espaços missionários em que os jesuítas atuaram, conheceram uma significativa renovação desde os finais do século XX, quando foi possível superar, a partir de uma produção acadêmica gestada no âmbito dos cursos de pós-graduação, em franca expansão na época, os tradicionais enfoques de elogio ou detratação. Na mesma medida, produziu-se, desde então, uma fecunda ampliação dos temas e das abordagens emprestadas às missóes, acompanhando a própria trajetória do campo da história naquele momento. Perspectivas que dirigiam seu interesse a questóes do campo da Antropologia relativas ao cultural e ao simbólico fecundaram, assim, as tradicionais histórias sobre esta temática.

Mais recentemente, a este movimento associou-se outro igualmente renovador, capaz de produzir uma mudança substancial na perspectiva pela qual se analisa o tema, dizendo respeito à recuperação, para as populações não europeias, de um lugar ativo na configuração dos elementos simbólicos e materiais que constituíram essa história. Tratou-se, fundamentalmente, no caso das Américas, como disse Celestino de Almeida (MOSTACCIO, 2010), de trazer as populações indígenas, dos "bastidores para o palco".

A partir dos anos 1990, a história dos índios, negligenciada pelos historiadores brasileiros, desenvolveu-se produtivamente no campo da Antropologia, em que surgiram as primeiras vozes críticas, questionando as velhas concepçóes que lhes reservavam o lugar de vítimas passivas dos processos de conquista e colonização. Antropólogos e historiadores como Manuela Carneiro da Cunha(ROBERTSON, 1997) e John Manuel Monteiro (ROBERTSON, 1997) representaram as primeiras tentativas de pensar neles como sujeitos históricos. Ambos foram as principais forças motrizes da história dos índios em contato com as sociedades coloniais e pós-coloniais, transformando-os em agentes históricos.

O diálogo com a Antropologia e a fecundidade das abordagens culturais e etno-históricas foram essenciais na reconfiguração do entendimento sobre a dinâmica indígena da missão. Isso em termos de estratégias, lógicas e práticas locais, associadas a uma adoção de certos dispositivos de poder - como a escrita - para fins diferentes daqueles do colonialismo.

Seguindo estes pressupostos teórico-metodológicos, foi possível, dessa maneira, superar a visão clássica que percebia as missóes como resultado do talento organizador dos jesuítas, considerando os indígenas como sujeitos passivos e submissos a ele. Outro elemento de "densificação" das histórias que se passaram a produzir, residiu em aportar uma compreensão mais complexa dos espaços missionários, no sentido de superar visóes idílicas de sociedades utópicas que puderam viver um “cristianismo feliz", tal como na definição de Ludovico Muratori (1743) ${ }^{1}$.

Trabalhos recentes, partindo de uma perspectiva mais complexa, concebem as missóes como espaços ao mesmo tempo religiosos, culturais e políticos, bem como de interaçóes e negociaçôes, individuais e coletivas, em que se transformam tradições, fundamentalmente nativas, mas nas quais, igualmente, sob certos aspectos, as europeias necessitaram ser adaptadas aos contextos locais. Se, por um lado, a análise "global” nos permite situar missóes no contexto das políticas de evangelização da Companhia de Jesus no Brasil, por outro lado, a perspectiva "local” integrará, modificará e/ou alterará a implementação de estratégias etnomissionais à escala mundial, bem como envolverá todos os aspectos da colonização europeia. Uma tensão entre agência política, cultura local e redes globais que alguns teóricos definiram como "glocal"2. 
Finalmente, podemos mencionar a importância de estudos empenhados em superar os prejuízos analíticos comportados por visóes compartimentadas do espaço missionário, construídas pelas historiografias nacionais decimonônicas. A elas se opõem, com evidente avanço interpretativo, perspectivas que problematizam a noção de fronteira e que apontam para a ideia de "região". Podemos, assim, concluir que os estudos contemporâneos sobre os espaços missionários são abertos e interdisciplinares, apontando para a importância de avaliações historiográficas que hoje em dia retomam e reinterpretam criticamente as fontes que permitem estudá-los.

Ao trabalho missionário jesuíta, que se estendeu desde o século XVI, para amplas porçóes do planeta, está associada uma notável produção historiográfica. Trata-se, portanto, de um tema que tem condensado fortemente, sob muitos aspectos, o interesse de historiadores de diferentes épocas e matrizes historiográficas.

Podemos dizer, efetivamente, que, no esforço de promover e "fazer memória" da sua atuação, as primeiras narrativas das missões foram construídas pelos próprios jesuítas coetâneos a elas, muitas vezes como exercício de propaganda das suas atividades apostólicas. Entretanto, há elementos para afirmarmos que o estudo dos espaços missionários permanece revestido de importância e densidade analítica no momento presente.

Ele é, assim, um bom ponto de partida para pensarmos, em vários sentidos, a nossa Modernidade. Entre os mais importantes ou evidentes desses sentidos, podemos apontar a atenção para as respostas locais (ou culturais) à expansão europeia iniciada junto com a Idade Moderna. É de fato possível, a partir daí, instalar-se uma profícua discussão sobre os processos de contato cultural e seus desdobramentos, tema absolutamente contemporâneo. Assim sendo, ao remetermo-nos inapelavelmente às questóes das alteridades, das culturas (e, por conseguinte, do relativismo cultural), de seus trânsitos, empréstimos e apropriaçóes, compreendemos que a importância dos espaços missionários jesuíticos justifica o número da Revista Anos 90 aqui apresentado.

Nosso Dossiê é uma amostra da variedade de reflexões que podem ser acionadas a partir da temática sobre a qual discorremos anteriormente, e de como tais problemáticas renovam uma historiografia que já é multissecular. Desejamos que a leitura seja proveitosa e estimuladora de novos trabalhos.

\title{
Notas
}

\begin{abstract}
${ }^{1}$ Erudito italiano, Ludovico Antônio Muratori (1672-1750) ficou particularmente conhecido por meio da obra Cristianesimo felice nelle missioni de' padri della Compagnia di Gesù nel Paraguay, publicada em Veneza, em 1743. A obra, conhecida como o Cristianismo Feliz defende o trabalho dos jesuítas nas Missões do Paraguai, quando elas eram fortemente criticadas.

${ }^{2}$ Como consequência da tese de doutoramento na Universidade de Chicago (1985), Negros da Terra. Índios e Bandeirantes nas Origens de São Paulo (1994), Monteiro deu visibilidade ao protagonismo dos índios na construção da sociedade colonial da capitania paulista, mostrando que as dinâmicas de conquista e colonização dependiam, em grande medida, das populações indígenas, cujas ações se baseavam nas dinâmicas de suas próprias sociedades.
\end{abstract}

\section{Referências}

ALMEIDA, Maria Regina Celestino. Os índios na história do Brasil. Rio de Janeiro: Editora FGV, 2010.

ARANHA, Paolo. "Glocal" Conflicts: Missionary Controversies on the Coromandel Coast between the XVII and XVIII centuries. In: CATTO, Michela; MONGINI, Guido; CARNEIRO DA CUNHA, Manuela. Antropologia do Brasil: mito, história, etnicidade. São Paulo: Brasiliense, [1992] 1998.

CARNEIRO DA CUNHA, Manuela. Introdução a uma história indígena. In: História dos Índios no Brasil. São Paulo: Companhia das Letras, 1998. p. 7-15. 
GRUZINSKI, Serge. Les quatre parties du monde. Histoire d'une mondialisation. Paris: La Martinière, 2004.

MELIÁ, Bartomeu. As missões jesuíticas nos sete povos das missões. IHU on-line, setembro de 2006. Disponível em: http://www.ihuonline.unisinos.br/artigo/407-as-missoes-jesuiticas-nos-sete-povos-das-missoes. Acesso em: 20 ago. 2020.

MOSTACCIO, Silvia (eds.). Evangelizzazione e globalizzazione. Le missioni gesuitiche nell'età moderna tra storia e storiografia, Itália: Società editrice Dante Alighieri, 2010. p. 79-83.

ROBERTSON, Roland. Glocalization: Time-Space and Homogeneity-Heterogeneity. In: FEATHERSTONE, Mike; LASH, Scot; ROBERTSON, Roland (eds.). Global Modernities. Londres: Thousand Oaks; Nova Delhi: Sage Publications, 1997. p. 25-44.

Recebido em: 10/10/2020

Aprovado em: 15/10/2020 